\title{
The Mediating Role of Competency on the Relationship between Training and Task Performance: Applied Study in Pharmacists
}

\author{
Jih-Hua Yang ${ }^{1}$, Shih-Chieh Fang ${ }^{1} \&$ Ching-Ying Huang ${ }^{1}$ \\ ${ }^{1}$ Department of Business Administration, National Cheng Kung University, Taiwan \\ Correspondence: Jih-Hua Yang, Department of Business Administration, National Cheng Kung University, Taiwan.
}

Received: September 17, 2017

Accepted: October 10, 2017

Online Published: October 26, 2017

doi:10.5430/ijba.v8n7p16

URL: https://doi.org/10.5430/ijba.v8n7p16

\begin{abstract}
This study aimed to determine the mediating role of competency (professional competency, technical competency, and core competency) between training and task performance in pharmacists. Questionnaire was the tool of collecting data from a sample of (210) pharmacists. The results of the study indicated that there is a positive effect of training on task performance. Also, there is full effect of the two mediator variables (professional competency; technical competency) and partial effect of the one mediator variable (core competency) on the relationship between independent and dependent variables.
\end{abstract}

Keywords: professional competency, technical competency, and core competency, training, task performance

\section{Introduction}

Since the concept of competency was made by Stogdill (1948), Katz (1955), and Mann (1965), theories and practices regarding competency have flourished. The notion of competency even widened into other fields, and studies of competency's link to managerial success and to effective performance in literature also proliferated, especially between the 1980s and 1990s (e.g., Boyatzis, 1982; Du Gay, Salaman, \& Rees, 1996; Lawler, 1994; Mansfield, 1996; McCall \& Lombardo, 1983; McLagan, 1996; Mirabile, 1997; Posner \& Kouzes, 1988; Spencer \& Spencer, 1993). The concept of Competency has considerable practicality and has contributed to improving both individual and organizational performance (McClelland, 1973; Spencer et al., 1993). This notion of competency can also serve in other areas, such as health care. In the face of today's fast-changing health care industry, raising the quality of medical services is essential. From the point of view of human resources, we must strengthen the capacity of health manpower beyond the traditional technical level. In practice, the medical industry has begun to attach importance to the competency of performance indicators. With these facts in mind, this study focuses on how competency mediator between the training and task performance and affects the output performance of medical personnel.

White (1959) proposed concept of competence as a business measurement, and linked it to ability as a performance motivator. McClelland (1973) refers to this concept and define competency, research indicates that an excellent worker performance, including attitude, cognitive and personality traits and other factors. These factors are called competency. Later, Boyatzis (1982) re-defined competence as a latent individual trait; this trait can lead to or produce superior efficiency of job performance. In summary, the definition of competency is rather vague (van der Klink and Boon, 2003). In order to ensure that the definition of competency would be comprehensive enough, scholars have chosen a broad definition (Delamare Le Deist \& Winterton, 2005). In this study, following to Spencer \& Spencer (1993) competency is defined as the potential underlying characteristic of individuals, characteristic that include more than only work-related duties, features which inspire higher expectations of employers, and are likely to positively influence the behavior and performance of individual performance (p.9).

In this study, competency (professional competency, technical competency, and core competency) plays mediator role between training and task performance that plays important role in improving the task performance in pharmacists.

\section{Theoretical Background and Hypotheses Development}

\subsection{Competency (Professional Competency, Technical Competency, and Core Competency)}

An overview and definition of competency was first proposed by McClelland (1973), who wrote a seminal paper entitled, "Testing for Competence Rather than for Intelligence." In the decades following McClelland's publication, 
many scholars also re-defined their research parameters based on the idea of competency (e.g., Boyatzis, 1982; Zemke, 1982; McLagan,1983; Cosfsky,1993; Spencer\&Spencer,1993; Dubois, 1993; Ledford, 1995; Ulrich, Brockbank, Yeung, \& Lake, 1995; Mirabile, 1997; Parry, 1998; Athey \& Orth, 1999; Lucia \& Lepsinger, 1999; Milkovich \& Newman, 1999; Roe, 2002; Jackson \& Schuler, 2002). Competency, as defined in the above article can be summarized by a few priorities: first, competency requires knowledge, skills and abilities; Secondly, competency can be observed and measured by concrete criteria; third, competency is associated with the performance output; and, finally, competency can be upgraded into something that can be taught and acquired through training. This study will use the definition made by Spencer \& Spencer (1993): competency is the basic potential characteristics of an individual, characteristics needed in work-related positions and will further expectations or affect individual behavior and performance. Spencer \& Spencer (1993) divided competency into the explicit and implicit. The explicit element includes skills and knowledge, and the implicit elements contain self-concept, traits and motives. Spencer \& Spencer (1993) focused on the explicit elements because they are most likely to be developed and are more cost-effective. This study focuses on the explicit elements of competency, and divides it into professional competency, technical competency, and core competency.

\subsection{Effects of Training on Task Performance}

Training increases employee knowledge, skills and attitudes in the process to achieving organizational goals. That is, using a systematic training program to train the professional knowledge, skills and attitudes needed to develop staff to meet the requirements of their work (Abiodun, 1999). Nadler \& Nadler (2012) assert that human resource development includes education and training. The purpose of education is to train employees, enhance their current work ability, and should coincide with organizational strategic planning. Its basic function is to enhance the ability of employees. Training is aimed at improving the performance of employees currently working and facilitates staff capability to adapt to organizational strategic planning under the new policies, procedures, etc. Its function is to enhance the ability of staff working. Training is aimed at improving the existing employee job performance (Gilley, Eggland, \& Gilley, 2002). When training is more focused and goal-oriented, in the short-term it is easier to see the results on job performance.(Thang, Quang, \& Buyens, 2010). Accordingly, the present study suggests that enhanced employee productivity or job performance is the main purpose of learning within an enterprise. The purpose of education and training is to provide program objectives and organizational learning experiences and opportunities which will enhance employee's current or future job performance and improve organizational performance. Based on the above reasoning, hypotheses were formulated as a follows:

Hypothesis 1: Training will be positively related to task performance.

\subsection{The Mediating Effect of Competency}

Subject competency and acquired learning (Nahavandi, 2009), are key to the promotion of self-efficacy. According to the social learning theory of self-efficacy theory point of view, past achievements, alternative experience, verbal persuasion, and evoked emotions will form self-efficacy, and then through self-awareness system this self-efficacy will be assessed. Personal success through past experience and personal observation, which will imitate the successful experience of others, will induce personal acceptance speech to encourage positive feelings. Individuals through evoking positive emotions, will enhance self-efficacy, which, when followed by self-assessment, will lead to strong confidence about things, causing further performance to be enhanced, thus having a strong positive impact on performance. Self-efficacy is the ability to continue to drive personal motivation and performance (Bandura, 1986), and self-efficacy will enhance individuals willing to accept the challenge and complete the challenge to get better performance (Bandura 1986; Wood \& Bandura, 1989). Based on the above reasoning, hypotheses were formulated as a follows:

Hypothesis 2: Professional competency will mediate the positive relationship between training and task performance. Hypothesis 3: Technical competency will mediate the positive relationship between training and task performance.

Hypothesis 4: Core competency will mediate the positive relationship between training and task performance. 


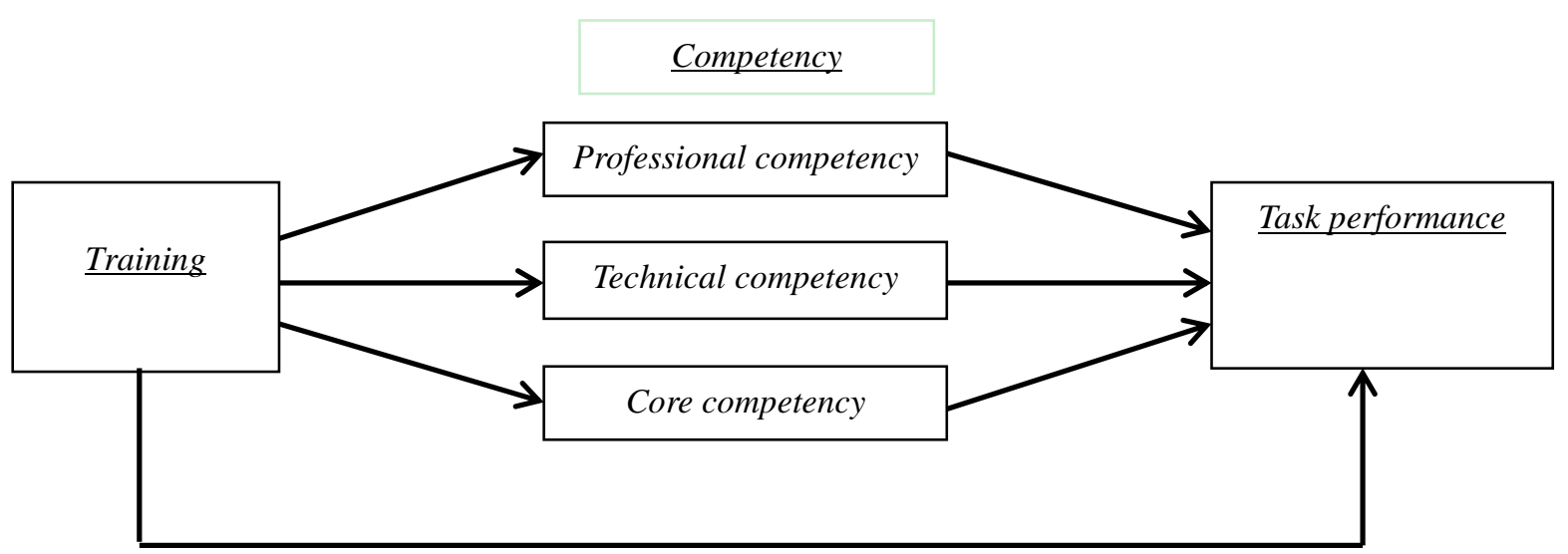

Figure 1. Theoretical model

\section{Method}

This study was based on a causal model which tries to explore the mediator effect of competency (professional competency, technical competency, and core competency) between training and task performance in pharmacists.

\subsection{Sample and Procedure}

In this study, in order to avoid common method variance (Podsakoff, MacKenzie, Lee, \& Podsakoff, 2003), using paired questionnaire. As subjects, this study uses pharmacists who were involved in a continuing education training process. In total, four echelons comprised of 240 pharmacists received training. After the training was completed, the researchers directly accessed pharmacists, pharmacists completed the competency and training questionnaire on the spot. And After six months, the workplace of the trained pharmacists' supervisor completed the performance questionnaire. Part of the questionnaire commissioned by the colleagues on behalf of the distributed and collected, in order to ensure confidentiality, the questionnaires were collected promptly after they were filled out and placed in the enclosed envelope. A total of 240 paper questionnaires were distributed, deduction of 30 parts handed in the questionnaires, and a total of 210 copies of valid questionnaires were obtained. The probability of total effective retrieval is $87.5 \%$. In this study, members of the medical industry served as the population of the study. Individual serve as the unit of measurement. Grassroots professional pharmacists who engaged in continuing education were asked to fill out the questionnaires. In the research project, pharmacists from different back grounds and work places participated: 144 respondents work in hospital pharmacies, 40 in community pharmacies, 15 in clinics, 11 are pharmaceutical or biotech drug dealers, making a total of 210 people. Regarding the participants' characteristics, 85 were male, 125 were female, with women accounting for $59.50 \%$ of the total; regarding age 92 of the respondents are between 21 and 30 years old, 52 between 31 and 40, 46 between 41 and 50, 15 between 51 and 60, and 5 are over 60 years old), The 21-30 year old group is the largest, and accounts for $43.80 \%$ of the total. As for education, the subjects can be broken down as follows: 7 bachelors (excluding) degree, 158 bachelor degrees, 41 master's degrees, and $4 \mathrm{PhDs}$. The largest group is made of up those with a bachelor's degree, accounting for $75.20 \%$ of the total. Regarding length of experience in the field, the respondents can be broken down as follows: 105 people (1-5 years), 31 people (6-10 years), 20 people (11-15 years), 27 people (16-20 years), 14 people (21-25 years), 13 people (26 - 30 years). Exactly half of the respondents have worked in the field for in 1-5 years, accounting for $50 \%$ of the total.

\subsection{Measures}

The survey items were provided using 5-point Likert scales with response scales being "strongly disagree"(1) and "strongly agree"(5). Dependent variables include task performance and context performance. Independent variable is training, dependent variable is task performance and mediator variables include professional competency, technical competency and core competency. Control variables include demographic variables. Pharmacists' work is statutory and exclusive. In the competency questionnaire design, business content which is controlled by pharmaceutical affairs regulations, were employed to measure the pharmacists' competency. According to the pharmaceutical affairs regulations, examine questions of competency scale through five experts, a total of 42 items, each including a professional competency, technical competency and core competency. A total of 18 questions focus on an examination of professional competency. A total of 11 questions survey technical competency. A total of 14 questions focus on core competency. The results of this study are reliability analysis. The overall Cronbach's $\alpha$ value of 0.961 
is good; the Cronbach's alphas are $0.939,0.944$, and 0.936 for professional competency, technical competency, and core competency, respectively. In terms of validity, we estimated two measurement models to verify the distinctiveness of the establishment of the one-factor and three-factor models. The results of the confirmatory factor analysis (CFA) suggest that the three-factor model provides a good fit $(\chi 2(816)=4988, \mathrm{p}<.001$, root mean square error of approximation $[\mathrm{RMSEA}]=0.15$, non-normed fit index $[\mathrm{NNFI}]=0.90$, comparative fit index $[\mathrm{CFI}]=0.90$, standardized root mean square residual $[\mathrm{SRMR}]=0.05)$. Regarding the topic of performance, we used the performance scale developed by Motowidlo \& Van Scotter, (1994). This task performance scale includes seven items. The Cronbach's $\alpha$ value of 0.907 is good. When looking at training, we used training scale developed by Giangreco et al., (2009). The training scale includes 13 items. The overall Cronbach's $\alpha$ value of 0.914 is good.

\section{Result}

\subsection{Correlation Analysis}

Table 1 shows descriptive statistics and inter-correlations for the study variables. The reliability coefficients were all greater than 0.91 . The age correlated positively with tenure $(\mathrm{r}=.84, \mathrm{p}<0.001)$. The tenure correlated positively with professional competence $(\mathrm{r}=.16, \mathrm{p}<0.05)$. The tenure correlated positively with core competence $(\mathrm{r}=.16, \mathrm{p}<0.05)$. All variables positively related to each other $(\mathrm{r}=.27 \sim .70, \mathrm{p}<0.001)$

Table 1. Means, standard deviations, and inter-correlations

\begin{tabular}{lccccccccc}
\hline variables & \multicolumn{1}{c}{$\mathrm{M}$} & $\mathrm{SD}$ & 1 & 2 & 3 & 4 & 5 & 6 & 7 \\
\hline 1. Age & 36.14 & 10.69 & - & & & & & & \\
2. Tenure & 9.63 & 8.93 & $.84 * * *$ & - & & & & & \\
3. T & 3.78 & 0.47 & .13 & .13 & $(.91)$ & & & & \\
4. PC & 3.64 & 0.63 & .11 & $.16^{*}$ & $.30^{* * *}$ & $(.94)$ & & & \\
5. TC & 4.07 & 0.54 & .10 & .13 & $.28^{* * *}$ & $.48^{* * *}$ & $(.94)$ & & \\
6. CC & 4.03 & 0.53 & .07 & $.16^{*}$ & $.40^{* * *}$ & $.52^{* * *}$ & $.77^{* * *}$ & $(.94)$ & \\
7. TP & 4.09 & 0.46 & .04 & .07 & $.27^{* * *}$ & $.45^{* * *}$ & $.62^{* * *}$ & $.70^{* * *}$ & $(.91)$ \\
\hline
\end{tabular}

Note: $\mathrm{N}=210$. Coefficient alphas are listed in parentheses along the diagonal.

$\mathrm{T}=$ training, $\mathrm{PC}=$ professional competency, $\mathrm{TC}=$ technical competency, $\mathrm{CC}=$ core competency,

$\mathrm{TP}=$ task performance $* p<0.05 \quad * * p<0.01 \quad * * * p<0.001$

\subsection{Hypothesis Testing}

Table 2 shows the results of hierarchical regression. We tested the hypotheses by regressing training and task performance on the control variables (step 1), the main effects of training (step 2). At step 2, the main effect of training on task performance has significant $(\beta=.261, \mathrm{p}<.001)$. Hypothesis 1 was supported.

Table 3 shows the results of hierarchical regression. We tested the hypotheses by regressing training and task performance on the control variables (step 1), the main effects of training (step 2), and the mediating effect of professional competency (step 3). At step 2, the main effect of training on task performance has significant $(\beta=.261$, $\mathrm{p}<.001)$, the mediating effect of professional competency on task performance has significant $(\beta=.408, \mathrm{p}<.001)$. Hypothesis 2 also was supported, as the strength of the beta for training decreased $(\beta=.145, \mathrm{p}<.005)$ when professional competency was included but remained significant, demonstrating partial mediation for task performance.

Table 4 shows the results of hierarchical regression. We tested the hypotheses by regressing training and task performance on the control variables (step 1), the main effects of training (step 2), and the mediating effect of technical competency (step 3). At step 2, the main effect of training on task performance has significant ( $\beta=.261, \mathrm{p}$ $<.001)$, the mediating effect of technical competency on task performance has significant $(\beta=.590, \mathrm{p}<.001)$. Hypothesis 3 was supported, as the beta for training became insignificant $(\beta=.106, \mathrm{p}>.005)$ when technical competency was included, demonstrating full mediation for task performance.

Table 5 shows the results of hierarchical regression. We tested the hypotheses by regressing training and task 
performance on the control variables (step 1), the main effects of training (step 2), and the mediating effect of core competency (step 3). At step 2, the main effect of training on task performance has significant $(\beta=.261, \mathrm{p}<.001)$, the mediating effect of core competency on task performance has significant $(\beta=.725, p<.001)$. Hypothesis 4 was supported, as the beta for training became insignificant $(\beta=-.025, \mathrm{p}>.005)$ when core competency was included , demonstrating full mediation for task performance.

Table 2. Hierarchical regression analysis

\begin{tabular}{lcc}
\hline \multirow{2}{*}{ Variables } & \multicolumn{2}{c}{ Task performance } \\
\cline { 2 - 3 } & Model 1 & Model 2 \\
\hline Control variable & & \\
$\quad$ age & .054 & -.072 \\
$\quad$ tenure & .115 & .096 \\
Independent variable & & \\
$\quad$ training & & $.261^{* * *}$ \\
\hline $\mathrm{R}^{2}$ & .006 & .073 \\
$\mathrm{~F}$ & .600 & $5.392^{* * *}$ \\
$\Delta \mathrm{R}^{2}$ & .006 & .067 \\
$\Delta \mathrm{F}$ & .600 & $14.896^{* * *}$ \\
\hline
\end{tabular}

Note: $\mathrm{N}=210 . * p<0.05 \quad * * p<0.01 \quad * * * p<0.001$

Table 3. Hierarchical regression analysis

\begin{tabular}{lccc}
\hline \multirow{2}{*}{ Variables } & \multicolumn{3}{c}{ Task performance } \\
\cline { 2 - 4 } Control variable & Model 1 & Model 2 & Model3 \\
$\quad$ age & -.054 & -.072 & -.026 \\
$\quad$ tenure & .115 & .096 & .007 \\
Independent variable & & & \\
$\quad$ training & & $.261^{* * *}$ & $.145^{*}$ \\
Mediator variable & & & \\
$\quad$ professional competency & & & $.408^{* * *}$ \\
\hline $\mathrm{R}^{2}$ & .006 & .073 & .221 \\
$\mathrm{~F} \quad$ & .600 & $5.392^{* * *}$ & $14.533^{* * *}$ \\
$\Delta \mathrm{R}^{2}$ & .006 & .067 & .148 \\
$\Delta \mathrm{F}$ & .600 & $14.896^{* * *}$ & $38.973^{* * *}$ \\
\hline
\end{tabular}

Note: $\mathrm{N}=210 . * p<0.05 \quad * * p<0.01 \quad * * * p<0.001$ 
Table 4. Hierarchical Regression Analysis

\begin{tabular}{lccc}
\hline \multirow{2}{*}{ Variables } & \multicolumn{3}{c}{ Task performance } \\
\cline { 2 - 4 } & Model 1 & Model 2 & Model3 \\
\hline Control variable & & & \\
$\quad$ age & .054 & -.072 & -.053 \\
$\quad$ tenure & .115 & .096 & .024 \\
Independent variable & & & \\
$\quad$ training & & $.261^{* * *}$ & .106 \\
Mediator variable & & & \\
$\quad$ technical competency & & & $.590^{* * * *}$ \\
\hline $\mathrm{R}^{2}$ & .006 & .073 & .391 \\
$\mathrm{~F}$ & .600 & $5.392^{* * *}$ & $32.906^{* * *}$ \\
$\Delta \mathrm{R}^{2}$ & .006 & .067 & .318 \\
$\Delta \mathrm{F}$ & .600 & $14.896^{* * *}$ & $107.115^{* * *}$ \\
\hline
\end{tabular}

Note: $\mathrm{N}=210 . * p<0.05 \quad * * p<0.01 \quad * * * p<0.001$

Table 5. Hierarchical regression analysis

\begin{tabular}{lccc}
\hline \multirow{2}{*}{ Variables } & \multicolumn{3}{c}{ Task performance } \\
\cline { 2 - 4 } & Model 1 & Model 2 & Model3 \\
\hline Control variable & & & \\
$\quad$ age & .054 & -.072 & .098 \\
$\quad$ tenure & .115 & .096 & -.122 \\
Independent variable & & & \\
$\quad$ training & & $.261^{* * *}$ & -.025 \\
Mediator variable & & & \\
$\quad$ core competency & & & $.725^{* * * *}$ \\
\hline $\mathrm{R}^{2}$ & .006 & .073 & .498 \\
$\mathrm{~F}$ & .600 & $5.392^{* * *}$ & $50.921^{* * * *}$ \\
$\Delta \mathrm{R}^{2}$ & .006 & .067 & .426 \\
$\Delta \mathrm{F}$ & .600 & $14.896^{* * *}$ & $173.929^{* * *}$ \\
\hline
\end{tabular}

Note: $\mathrm{N}=210 . * p<0.05 \quad * * p<0.01 \quad * * * p<0.001$

\section{Discussion}

\subsection{Discussion and Conclusions}

In terms of the control variables, pharmacists age and seniority, regardless of task performance, do not seem to be significant. In the main effect, however, this study found that there is a positive role of training in improving task performance. This study finding fit into the context of Khanfar's (2014) study, the results affirmed that there is a 
positive impact of training on the job performance.

Regarding the mediator effect, the results of the study revealed that there is a significant impact of professional competency, technical competency, and core competency on the relationship between the training and task performance. The main reason is that pharmacists have expertise and should be considered technical workers. The medical system and the work environment do not allow for any negligence. For most of the pharmacists' work content, professional-oriented results are significantly better than experience-oriented results. This was agreed and extended with the study results of (McClelland, 1973; Spencer et al., 1993), competency has considerable practicality and has contributed to improving both individual and organizational performance.

\subsection{Contribution}

First, since the 1940s, scholars have come to pay more attention to the impact of the performance of competency. This study proposes competency, aimed at developing further insight into competency perspectives as well as the mediating role of training and performance. Secondly, the main effect of the present study, regarding the self-efficacy perspective is worth noting. Competency will through individual self-efficacy plays a mediating mechanism between training and mission performance. This information should extend the scope of self-efficacy (Bandura, 1977). Third, from the practical perspective, competency has become an important indicator of the medical industry. The results of this study make clear that whether it is through professional competency, technical competency, and core competency, competency has a significant impact on task performance. Therefore, this study makes the following recommendations; first, in addition to strengthening the training, the practice of professional and technical competency should be further strengthened in the field of pharmacy care-related businesses, to enhance the quality of medical care and provide clients with more substantive help. In addition, the pharmacy industry's continuing education is often limited to those forced to participate, which can cause distress, in particular, the timing of the implementation of surface pharmacists often becomes troubled. This study suggests that if we make modest improvements in the education and training to make them more flexible, for example, open online credit courses to enable trainees' pharmacists to customize the selection of learning places, it should increase their learning willingness and strengthen professional and technical competency in pharmacy care business.

\subsection{Limitations and Future Research}

In this study, the researcher seeks to improve the design and analysis, but there are still several points which should be noted.First, regarding external validity issues, the present study's sample survey of pharmacists failed to include other medical personnel, such as doctors, nurses and hospital administration staff. Second, in terms of research scale, in the scale competency, the present study, although substantially complete in its efforts at sorting out professional competency, technical competency and core competency, still finds it difficult to avoid the problem of lack of comprehensiveness. We propose that future research should focus on the integrity of the medical industry functions scale in order to enhance the quality scale. Third, as for training evaluation and common method variance square, although the present study adopts the more practical value of the first stage of the reaction level, the questionnaire respondents participated in training provided by the staff, however, to be able to arrive at a more complete understanding of education and training, it is recommended that in future research projects the scholars should simultaneously use the full four-stage level.

\section{References}

Abiodun, E. (1999). Human Resources management, an overview. Concept Publication, Shomolu, Lagos, pp. 110-121.

Athey, T. R., \& Orth, M. S. (1999). Emerging competency methods for the future. Human Resource Management, 38, 215-226. https://doi.org/10.1002/(SICI) 1099-050X(199923)38:3<215::AID-HRM4>3.0.CO;2-W

Bandura, A. (1986). Social foundations of thought and action: A social cognitive theory. Prentice-Hall, Inc.

Boyatzis, R.E. (1982). The Competent Manager: A Model for Effective Performance. New York: Wiley

Cofsky, K. M. (1993). Critical Keys to Competency-Based Pay. Compensation and Benefits Review, 25(6), 46-52. https://doi.org/10.1177/088636879302500609

Delamare Le Deist, F., \& Winterton, J. (2005). What is competence? Human Resource Development International, 8, 27-46. https://doi.org/10.1080/1367886042000338227

Du Gay, P., Salaman, G., \& Rees, B. (1996). The conduct of management and the management of conduct: Contemporary managerial discourse and the constitution of the 'competent' manager. Journal of Management Studies, 33, 263-282. https://doi.org/10.1111/j.1467-6486.1996.tb00802.x 
Dubois, D.D. (1993). Competency-Based Performance Improvement: A Strategy for Organizational Change. Amherst: HRD Press.

Giangreco, A., Sebastiano, A., \& Peccei, R. (2009). Trainees' reactions to training: an analysis of the factors affecting overall satisfaction with training. The International Journal of Human Resource Management, 20(1), 96-111. https://doi.org/10.1080/09585190802528417

Gilley, J. W., Eggland, S. A., \& Gilley, A. M. (2002). Principles of human resource development. Basic Books.

Jackson, S. E., \& Schuler, R. S. (2002). Managing individual performance: An individual perspective. In S. Sonnentag (Ed.), Psychological management of individual performance (pp. 371-390). New York: John Wiley and Sons.

Katz, R. L. (1955). Skills of an effective administrator. Harvard Business Review, 33, 33-42.

Khanfar, S. M. (2014).Training and its Important in the Efficiency of Employees' Performance in Five -Star Hotels in Jordan. Journal of Business Studies Quarterly, 6(2), 137-158.

Lawler, E. E. (1994). From job-based to competency-based organizations. Journal of Organizational Behavior, 15, 3-15. https://doi.org/10.1002/job.4030150103

Ledford, G.E. Jr. (1995). Paying for the skills, knowledge, and competencies of knowledge workers. Compensation and Benefits Review, 27(4), 55-62. https://doi.org/10.1177/088636879502700409

Lucia, A. D., \& Lepsinger, R. (1999). The art and science of competency models: Pinpointing critical success factors in organizations. San Francisco: Jossey-Bass.

Mann, F. C. (1965). Toward an understanding of the leadership role in formal organization. In R. Dubin, G. C. Homans, F. C. Mann, \& D. C.Miller (Eds.), Leadership and productivity: Some facts of industrial life (pp. 44-78). San Francisco: Chandler.

Mansfield, R. S. (1996). Building competency models: approaches for HR professionals. Human Resource Management, 35, 7-18. https://doi.org/10.1002/(SICI)1099-050X(199621)35:1<7::AID-HRM1>3.0.CO;2-2

McCall, M. W., \& Lombardo, M. M. (1983). Off the track: Why and how successful executives get derailed. Greensboro, NC: Center for Creative Leadership.

McClelland, D. C. (1973). Testing for competence rather than for" intelligence." American psychologist, 28(1), 1-14. https://doi.org/10.1037/h0034092

McClelland, D. C., \& Boyatzis, R. E. (1982). Leadership motive pattern and long term success in management. Journal of Applied Psychology, 67, 737-743. https://doi.org/10.1037/0021-9010.67.6.737

McLagan, P.A. (1983). Models for Excellence. The Conclusions and Recommendations of the ASTD Training and Development Competency Study. Washington, D.C.: American Society for Training and Development.

Milkovich, T. G., \& Newman, M. J. (1999). Compensation. N.Y.: McGraw Hill

Mirabile, R. J. (1997). Everything you wanted to know about competency modeling. Training and Development, 51, 73-77.

Motowidlo, S. J., \& van Scotter, J. R. (1994). Evidence that task performance should be distinguished from contextual performance. Journal of Applied Psychology, 79, 475-480. https://doi.org/10.1037/0021-9010.79.4.475

Nadler, Z., \& Nadler, L. (2012). Designing training programs. Routledge.

Nahavandi, A. (2009). The art and science of leadership. Pearson Prentice Hall.

Parry, S. B. (1998). Just what is a competency? And why should you care? Training, 35(6), 58-64.

Podsakoff, P. M., MacKenzie, S. B., Lee, J.-Y., \& Podsakoff, N. P. (2003). Common method biases in behavioral research: A critical review of the literature and recommended remedies. Journal of Applied Psychology, 88, 879-903. https://doi.org/10.1037/0021-9010.88.5.879

Posner, B. Z., \& Kouzes, J. M. (1988). Development and validation of the Leadership Practices Inventory. Educational and Psychological Measurement, 48, 483-496. https://doi.org/10.1177/0013164488482024

Roe, R. A. (2002). What Makes a Competent Psychologist?. European Psychologist, 7, 192-202. https://doi.org/10.1027//1016-9040.7.3.192 
Spencer, L. M., \& Spencer, S. M. (1993). Competence at work: Models for superior performance. New York: Wiley.

Stogdill, R. M. (1948). Personal factors associated with leadership: A survey of the literature. Journal of Psychology, 25, 35-71. https://doi.org/10.1080/00223980.1948.9917362

Thang, N. N., Quang, T., \& Buyens, D. (2010). The Relationship between Training and Firm Performance: A Literature Review. Research and Practice in Human Resource Management, 18(1), 28-45.

Ulrich, D., Brockbank, W., Yeung, A. K., \& Lake, D. G. (1995). Human resource competencies: An empirical assessment. Human Resource Management, 34, 473-495. https://doi.org/10.1002/hrm.3930340402

Van der Klink, M. R., \& Boon, J. (2003). Competencies: The triumph of a fuzzy concept. International Journal Human Resources Development and Management, 3, 125-137. https://doi.org/10.1504/IJHRDM.2003.002415

White, R. W. (1959). Motivation reconsidered: the concept of competence. Psychological Review, 66, 297-333. https://doi.org/10.1037/h0040934

Wood, R., \& Bandura, A. (1989). Social cognitive theory of organizational management. Academy of management Review, 14(3), 361-384.

Zemke, R. (1982). Job Competencies: Can they Help you Design Better Training?. Training, 19(5), 28-31. 